\section{OTR.0I - Combinando análises de citações de patentes e TRIZ em um método simples para a identificação de grandes inovações biotecnológicas}

Christiane de Fátima Silva Marques ${ }^{1 \star}$; Marcus Vinícius de Araújo Fonseca² ${ }^{2}$

1Fiocruz/Bio-Manguinhos;

2UFRJ - Universidade Federal do Rio de Janeiro.

\section{Introdução:}

A análise das citações de patentes é uma das ferramentas mais comuns para medir sua influência sobre desenvolvimentos tecnológicos subsequentes. As citações têm sido altamente correlacionadas com importância técnica e retornos sociais da inovação. Essa análise pode ser usada para assessorar projetos de $\mathrm{P} \& \mathrm{D}$, monitorar tecnologias, identificar alternativas técnicas e fontes de expertise, ajudando a entender as relações entre tecnologias e suas consequências para a organização e a indústria, bem como avaliar o impacto das políticas de inovação. Desenvolvida por Genrich Altshuller na década de 1940, a Teoria da Solução de Problemas Inventivos (TRIZ) é um dos métodos heurísticos modernos para ideação de novos produtos, seguindo regras e padrões presentes no processo criativo. Baseia-se em um número reduzido de possibilidades universais para resolver problemas, amplamente aplicáveis a campos distintos, e resulta da análise de milhares de documentos de patentes de diversas áreas. Os elementos da TRIZ compõem um método sistemático para resolução de problemas e aprendizado organizacional, que leva a soluções satisfatórias para gargalos técnicos, bem como identifica tendências e oportunidades tecnológicas como cenário de base para novas invenções.

\section{Objetivo:}

O presente estudo combina a contagem de citações de patentes e TRIZ em um método para a identificação das principais invenções de impacto em um campo de tecnologia específico. A biotecnologia moderna foi o modelo de estudo, por ser área altamente dinâmica, densa tecnologicamente e baseada no conhecimento, onde patentes são um instrumento crucial para a proteção da propriedade intelectual.

\section{Metodologia:}

A combinação da análise de citações e nível inventivo foi aplicada a 0,3\% das patentes mais citadas em biotecnologia aplicada à saúde humana, focalizando o nicho de reagentes de diagnóstico in vitro. A base de dados on-line da Thomson Innovation (Derwent Innovations Index) foi fonte dos documentos. A análise incluiu a perspectiva dos princípios inventivos, parâmetros de engenharia e níveis inventivos TRIZ.

\section{Resultado:}

Todas as invenções significativas na biotecnologia moderna compuseram o grupo resultante, confirmando que o método proposto foi capaz de identificar as melhores e mais inovadoras patentes em uma área específica de P\&D. A lista robusta de patentes fornece informações básicas sobre as tecnologias, sem uma quantidade esmagadora de documentos e necessidade de aplicativos caros e complexos. A metodologia proposta e a lista gerada também podem ser utilizadas em estudos patentométricos mais aprofundados sobre tecnologias ou campos técnicos específicos.

\section{Conclusão:}

A combinação dessas informações de análise de patentes como ferramenta para gerenciamento de inovação também pode ser adaptada a outras áreas do conhecimento e ajudar estudos acadêmicos, corporativos e governamentais, por exemplo, aumentando o impacto da inovação em iniciativas de pesquisa e desenvolvimento em todo o mundo e, consequentemente, o desempenho da indústria.

Palavras-chave: TRIZ; patentometria; biotecnologia 